\title{
Identifikasi Sebaran Episenter Dan Hiposenter Gunungapi Guntur Berdasarkan Data Seismik dengan Menggunakan Metode Geiger
}

\author{
Nandaru Diaz $^{1^{*}} \mid$ Ni Kadek Sugestiani ${ }^{1}$ Gede Suantika ${ }^{2}$ \\ IJurusan Fisika, Fakultas Matematika dan Ilmu Pengetahuan Alam, Universitas Udayana, \\ ${ }^{2}$ Pusat Vulkanologi dan Mitigasi Bencana Geologi, Badan Geologi
}

\begin{abstract}
Abstrak
Telah dilakukan identifikasi hiposenter gempa Gunungapi Guntur pada bulan Juni 2016 dengan menggunakan metode Geiger. Lokasi hiposenter gempabumi penting dilakukan untuk identifikasi sumber gempa, pemetaan sebaran gempa dan analisis kegempaan. Hasil penelitian menunjukkan pola sebaran episenternya terdistribusi pada gugusan komplek Gunung Guntur sampai Gunung Masigit pada kedalaman $0-10 \mathrm{~km}$ yang dihitung dari puncak Gunungapi Guntur.
\end{abstract}

Kata kunci: Gunungapi, gempa, Geiger, gunung guntur

\section{Pendahuluan}

Gunungapi Guntur merupakan salah satu gunungapi aktif di Indonesia. Dalam catatan sejarahnya gunung ini seringkali meletus baik secara eksplosif (ledakan) maupun leleran lava yang dapat membahayakan daerah sekitarnya. Pada tahun 1800-1847 tercatat terjadinya letusan lebih dari 21 kali [1]. Data kegempaan Gunungapi Guntur selama 20 tahun terakhir menunjukkan kecenderungan peningkatan jumlah gempa vulkanik. Jumlah gempa vulkanik pada bulan Oktober 1997, Mei 1999, November 2002, dan Juni 2005 telah melebihi angka 100. Kemudian pada bulan September 2011 jumlah gempa vulkanik meningkat menjadi 277 gempa dan pada bulan September 2013 kembali meningkat menjadi 348 gempa [2]. Adanya peningkatan kegempaan ini tentunya harus diantisipasi dengan baik. Salah satu bentuk antisipasi adalah dengan melakukan mitigasi terhadap aktivitas vulkanik yang terjadi dan memonitoring kegempaan dibawah Gunungapi Guntur. Salah satu langkah mitigasi yang dilakukan adalah dengan melakukan analisis kegempaan. Hal ini perlu dilakukan mengingat banyaknya jumlah penduduk yang bermukim di sekitar Gunungapi Guntur.

\section{Landasan Teori}

Gunungapi Guntur atau lebih dikenal dengan Gunung Guntur adalah nama sebuah puncak dari suatu kelompok gunungapi yang disebut dengan Komplek Gunung Guntur. Di era tahun 1800-an, Gunung Api Guntur merupakan gunung paling aktif di Indonesia, bahkan mengalahkan Gunung Api Merapi di Jawa Tengah. Seorang naturalis Belanda kebangsaan Jerman,Franz Wilhelm Junghuhn, rajin menuliskan laporan tentang betapa aktifnya Gunungapi Guntur dalam bukunya yang berjudul 13 Goentoer, Java Tweede Afduling, De Vulkaan en Vulkanische Verschjnslen West-en Midden-Java (1850).Sejak letusan terakhir yang terjadi pada tahun 1847 sampai saat ini (154 tahun)tidak pernah terjadi letusan lagi. Aktifitas gunungapi ini selanjutnya dicirikan dengan terekamnya gempa-gempa vulkanik yang berkisar antara 20-30 kejadian perbulan [3].

Lokasi hiposenter dihitung dengan asumsi bahwa batuannya homogen dengan cepat rambat gelombang primer $2,76 \mathrm{~km}$ perdetik. Sumber gempanya terkonsentrasi secara vertikal di bawah puncak Kawah Gunungapi Guntur dengan kedalaman 0-5 km, serta di sekitar Kawah Kamojang, Gandapura dan Gunung Putri dengan kedalaman 5-10 km [4]. Gempa-gempa yang terjadi di bawah puncak diduga dikarenakan oleh rekahan-rekahan kecil dalam batuan pipa kepundan hasil erupsi sebelumnya. Dengan melihat penyebaran hiposenter dan struktur geologi permukaanterlihat bahwa

\footnotetext{
*Penulis Korespondensi. Email: nandaru diaz@student.unud.ac.id
} 
mekanisme sumber gempa di daerah Kamojang umumnya dihasilkan oleh adanya pergeseran sesar dengan arah timur laut dan barat daya.

Pos Pengamatan Gunungapi Guntur juga berfungsi sebagai "Pos Regional Center" yang menerima juga kegempaan dari Gunungapi Papandayan dan Gunungapi Galunggung. Data kegempaan Gunungapi Guntur - Papandayan dan Gunungapi Galunggung diteruskan ke Pusat Vulkanologi dan Mitigasi Bencana Geologi di Bandung dengan teknologi VSAT. Lokasi stasiun pemantauan Gunungapi Guntur ditunjukkan oleh Tabel 1.

Tabel 1. Lokasi Stasiun Pemantau Gunung Api Guntur

\begin{tabular}{|l|c|c|c|}
\hline \multicolumn{1}{|c|}{ Stasiun } & Longitude (UTM) & Latitude (UTM) & $\begin{array}{c}\text { Ketinggian } \\
(\mathbf{m ~ d p l )}\end{array}$ \\
\hline Sodong (SDG) & 107,8456 & $-7,16168$ & 1582 \\
\hline Citiis (CTS) & 107,8592 & $-7,15287$ & 1450 \\
\hline Kiamis (MIS) & 107,7504 & $-7,19859$ & 1650 \\
\hline Masigit (MSG) & 107,8413 & $-7,14909$ & 2190 \\
\hline Kabuyutan (KBY) & 107,8481 & $-7,15425$ & 1930 \\
\hline Legokpulus (LGP) & 107,8150 & $-7,17504$ & 1400 \\
\hline
\end{tabular}

Ref [5]

\section{Metode Penelitian}

Data yang digunakan pada penelitian ini adalah data sekunder hasil rekaman gempa diperoleh beberapa informasi yaitu gerakan awal sinyal gelombang, waktu tiba gelombang primer, waktu tiba gelombang sekunder, durasi gempa dan selisih waktu tiba gelombang primer dan sekunder yang direkam oleh 6 seismograf di Gunungapi Guntur. Data yang didapatkan terdiri dari parameter gempabumi berupa waktu tiba gelombang (origin time), lintang, bujur dan kedalaman. Wilayah penelitian berada pada koordinat $7,00^{\circ} \mathrm{LS}-7,25^{\circ} \mathrm{LS}$ dan $170,65^{\circ} \mathrm{BT}-180,00^{\circ} \mathrm{BT}$. Penentuan hiposenter gempabumi dilakukan dengan software Geiger Adaptive Damping (GAD) serta pemetaan hasil sebaran hiposenter dipetakan menggunakan software Origin 8.

\section{Hasil dan Pembahasan}

Hasil perolehan kedalaman gempa Gunungapi Guntur pada bulan Juni tahun 2016 didapatkan kejadian gempa vulkanik tipe A atau vulkanik dalam terjadi 25 kali kejadian dan vulkanik tipe B atau vulkanik dangkal terjadi 17 kali kejadian gempa. Selain itu tercatat juga terjadi gempa tektonik lokal sebanyak 13 kali kejadian, 1 kali kejadian gempa tektonik terasa dan gempa tektonik jauh terjadi sebanyak 4 kali. Hiposenter yang digambarkan pada Gambar 2 dan Gambar 3 diukur dari Puncak Gunungapi Guntur pada elevasi +2249 mdpl sebagai titik 0 .

Klasifikasi gempa bumi yang digunakan penulis adalah klasifikasi berdasarkan kedalaman gempa dan jarak episenter dari puncak Gunung Guntur. Sebaran gempa tektonik lokal dan tektonik jauh terjadi antara 20-58 km arah barat hingga selatan Gunung Guntur. Hal ini tepat terjadi di daerah Garut barat yang didominasi lempeng tektonik aktif sehingga sering terjadi getaran-getaran tektonik. Sumber gempa vulkanik terkonsentrasi secara vertikal di bawah puncak Gunung Guntur dengan kedalaman 0$10 \mathrm{~km}$. Sedangkan gempa tektonik diklasifikasikan pada gempa yang tercatat lebih dari $20 \mathrm{~km}$ dari puncak Gunung Api Guntur. Hasil pemetaan sebaran episenter gempa di permukaan bumi ditunjukkan oleh Gambar 1. 


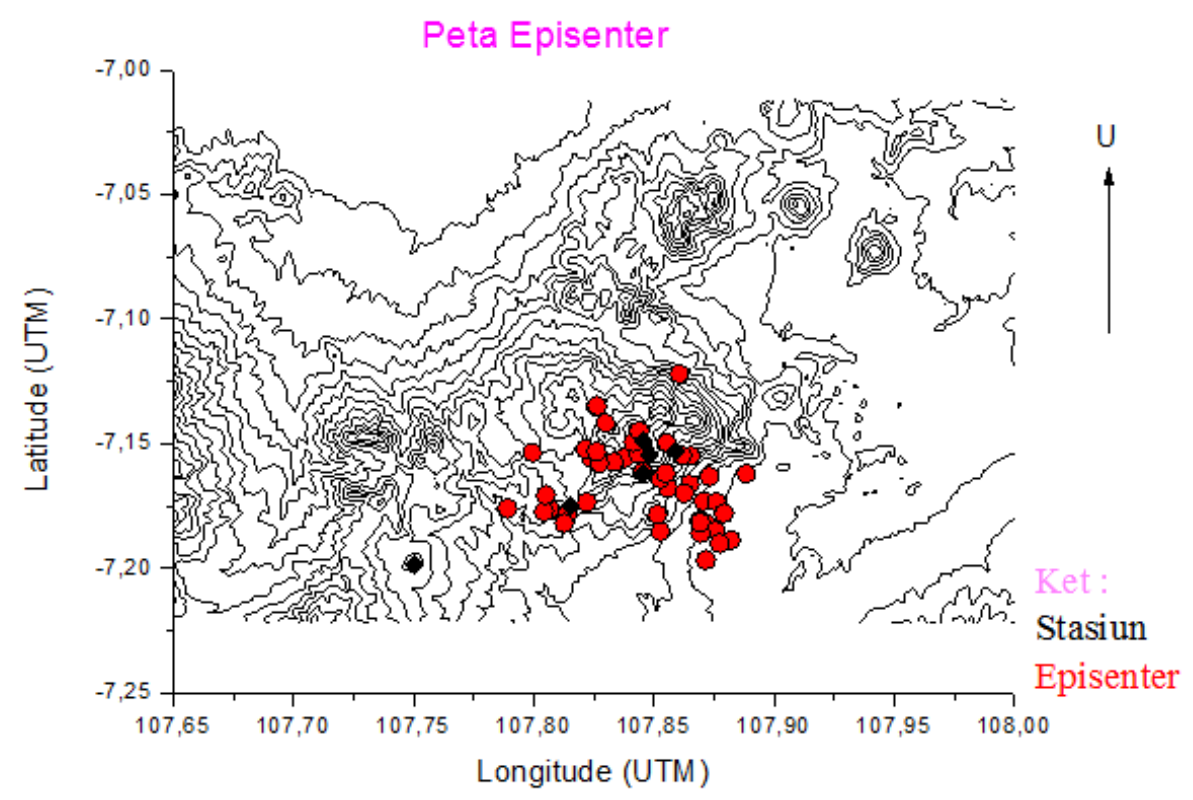

Gambar 1. Hasil Pemetaan Sebaran Episenter Gempa di Permukaan Bumi

Gambar 1 lingkaran merah menunjukkan sebaran episenter dan warna hitam merupakan stasiun pos pengamatan Gunungapi. Hasil yang diperoleh menunjukkan bahwa sebaran episenter gempa vulkanik dan tektonik pola sebaran episenternya terdistribusi ke arah yang berbeda dalam gugusan komplek Gunung Guntur. Persebarannya dominan pada kompleks Guntur-Masigit. Perubahan episenter yang cukup signifikan dibandingkan dengan data episenter gempa-gempa sebelumnya yang berada pada area kawah gunungapi Guntur-Masigit-Gandapura.

Berdasarkan hiposenter dari beberapa gempa yang terjadi pada bulan Juni tahun 2016, diperoleh pusat gempa banyak terjadi pada sekitar kawah Gunungapi Guntur-Masigit yang berada pada kedalaman lebih dari 1 hingga $10 \mathrm{~km}$ dari puncak. Pola sebaran kedalamannya paling dalam berada tepat dibawah Gunung Guntur. Pola penampang hiposenter pada kedalaman lebih dari 1 hingga $10 \mathrm{~km}$ dari puncak arah Utara-Selatan ditunjukkan oleh Gambar 2 dan pola penampang hiposenter pada kedalaman lebih dari 1 hingga $10 \mathrm{~km}$ dari puncak arah Barat-Timur Gambar 3.

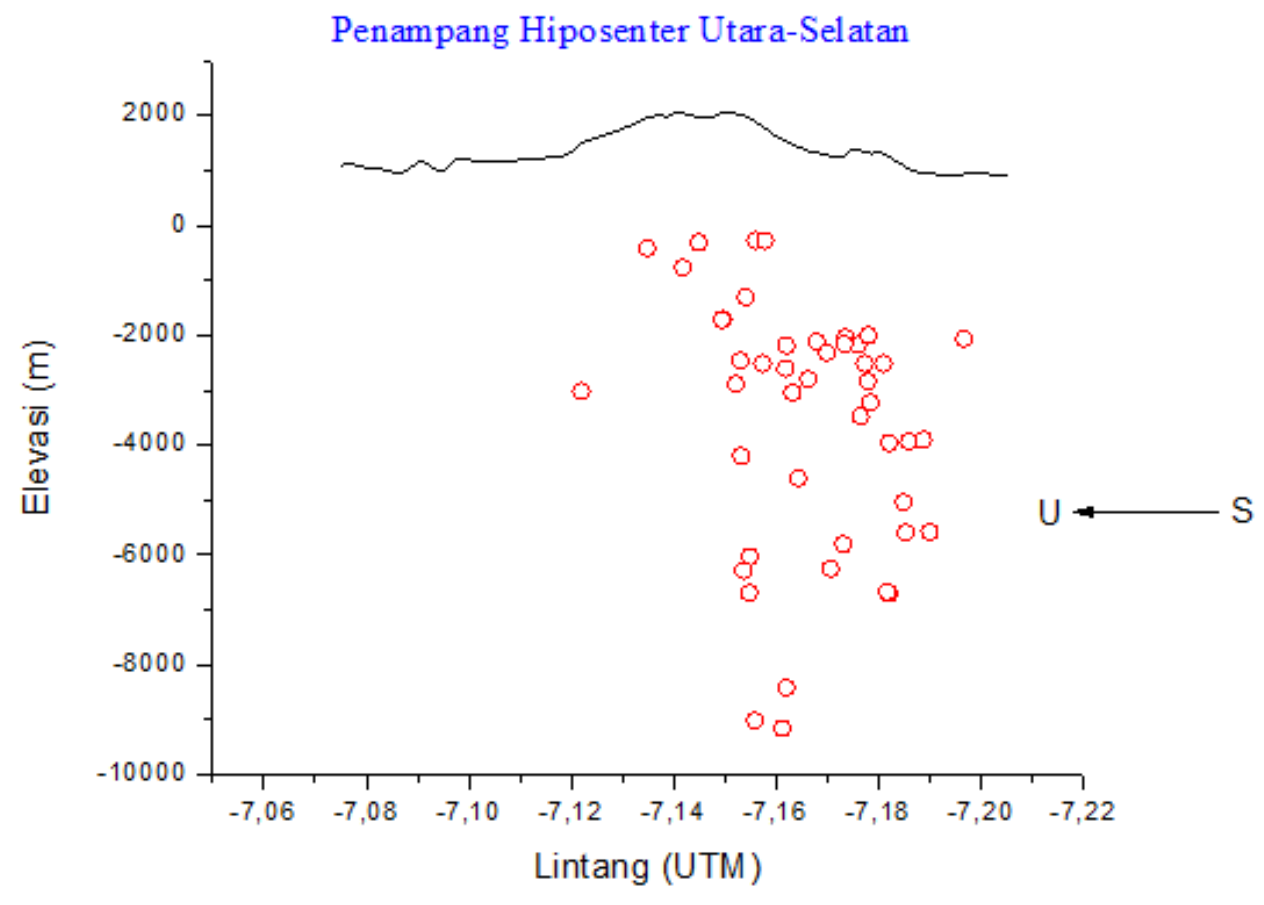


Jurnal SEMAR Vol. 8 No. 2, 2019 hal. $17-20$

ISSN: 2302-3937 | Copyright @ LPPM Universitas Sebelas Maret

Homepage: https://jurnal.uns.ac.id/jurnal-semar

Gambar 2. Hasil Pemetaan Sebaran Hiposenter Ditinjau dari Arah Utara-Selatan

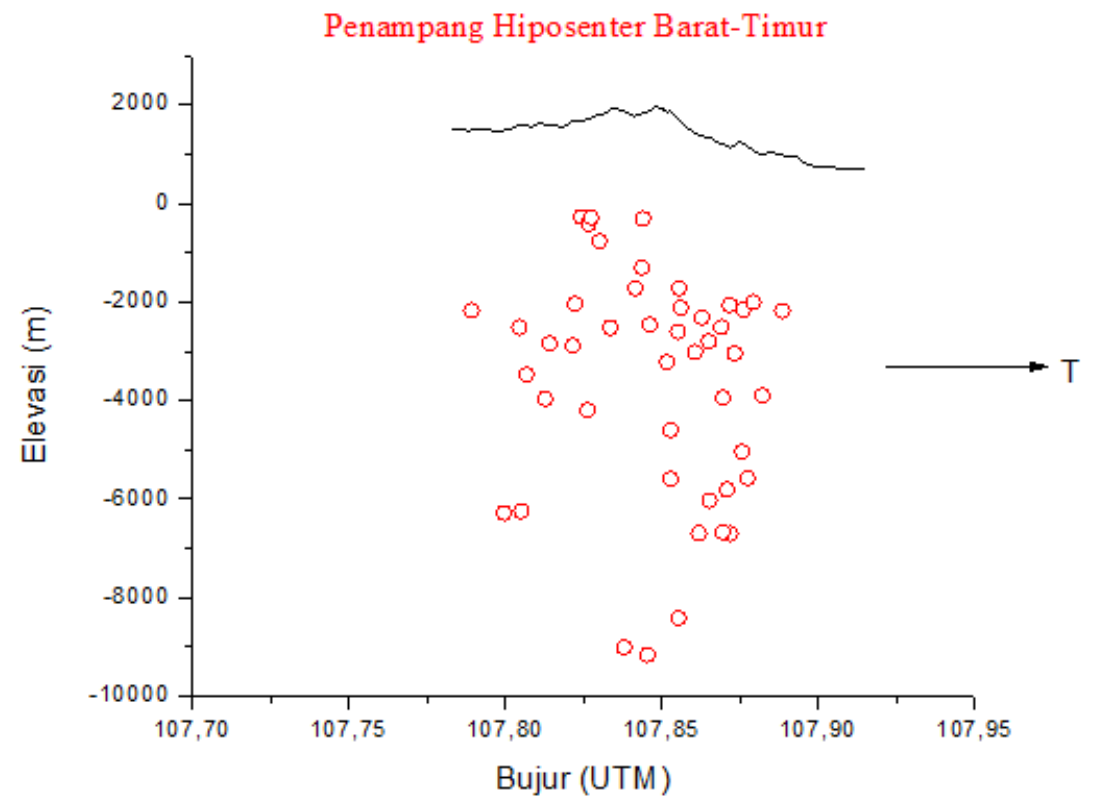

Gambar 3. Hasil Pemetaan Sebaran Hiposenter Ditinjau dari Arah Barat-Timur

Hasil penelitian penulis tidak memasukkan semua data gempa yang terekam pada seismograf sebab penulis fokus kepada episenter dan hiposenter gempa serta klasifikasi gempa vulkanik dan gempa yang kedalamannya kurang dari $10 \mathrm{~km}$. Hasil persebaran episenter dan hiposenter gempa cukup bagus karena nilai probable error terlihat pada hasil result GADtester kurang dari 1.

\section{Kesimpulan}

Gempa vulkanik bulan Juni tahun 2016 terjadi sebanyak 35 event yang terdiri gempa vulkanik tipe A atau vulkanik dalam terjadi 20 event dan vulkanik tipe B atau vulkanik dangal terjadi 15 event. Hasil pemetaan hiposenter dan episenter gempa vulkanik terjadi pada sekitar kawah Gunungapi Guntur sampai Gunung Masigit yang berada pada kedalaman lebih dari 1 hingga $10 \mathrm{~km}$ dari puncak.

\section{Ucapan Terimakasih}

Ucapan terima kasih penulis sampaikan kepada Pusat Vulkanologi dan Mitigasi Bencana Geologi atas kesediaannya dalam memberikan data yang telah digunakan dalam penelitian ini.

\section{Pustaka}

[1] Rasjid, S.A., Sumaryono, Sugiyo, dan Kusma, 1985, Laporan Pengamatan Seismik G. Guntur Citiis Garut Bulan Januari-Februari 1985, Proyek Penyelidikan dan Pengamatan Gunungapi Direktorat Vulkanologi Nomor 287/DV/1985, 1985, halaman 1-8.

[2] Basuki, A., Thesis: Penentuan Lokasi Hiposenter Gempa Vulkanik-Tektonik dan Struktur Kecepatan Gelombang Seismik di Gunung Guntur, Bandung: Institut Teknologi Bandung, 2015

[3] _ 2011, Data Dasar Gunungapi Indonesia Edisi kedua, Badan Geologi Kementerian Energi dan Sumber Daya Mineral.

[4] Suantika, G., Iguchi, M., Sutawidjaja, I.S., dan Yamamoto, K., Characteristic of Volcanic Earthquakes around Guntur Volcano West Java Indonesia, Symponsium of Indonesia- Japan Project, Bandung, 1998, halaman 72-80.

[5] Sudradjat, A., Modjo, S., dan S. Kartijoso, 1991, Berita Berkala Vulkanologi Edisi Khusus G. Guntur No. 169 Tahun 1991, Direktorat Vulkanologi. 